\title{
Structural property losses from tornadoes in Florida
}

James B. Elsner*, Emily Ryan and Georgianna Strode

Florida State University, Tallahassee, Florida

${ }_{4}^{*}$ Corresponding author address: James B. Elsner, Department of Geography, Florida State Univer-

5 sity, 113 Collegiate Loop, Tallahassee, FL 32301.

6 E-mail: jelsner@fsu.edu 


\section{ABSTRACT}

Property losses from tornadoes in Florida are estimated by combining a one-

${ }_{8} \mathrm{~km}$ spatial grid of structural values from the Department of Revenue's 2014

9 cadastral database with historical tornado events since 1950. There are 91,180

10 cells in the state with at least some structural value. Total and residential 11 structural values total \$942 Billion and \$619 Billion, respectively. Over the period 1950 through 2015 there were 3,233 individual tornado reports in the

${ }_{13}$ state with a peak frequency during July. Property value exposed to torna14 does is estimated using a geometric model for the path. Annual statewide 15 total and residential structural property exposure to tornadoes is estimated ${ }_{16}$ at $\$ 171$ Million and $\$ 103$ Million, respectively. Property exposure to torna17 does peaks in February although the number of tornadoes peaks in Septem192007 and exposures. A doubling of the residential exposure increases actual 20 recorded losses by $26 \%$ since 2007 and a doubling of non-residential exposure ${ }_{21}$ increases losses by $21 \%$ controlling for changes over time. Randomization of ${ }_{22}$ the historical tornado paths provides alternative exposure scenarios that are used to determine the probability of extreme loss years. Results from the ${ }_{24}$ Monte Carlo algorithm indicate a $1 \%$ chance that the annual loss will exceed actions. 


\section{Introduction}

A tornado is a violently rotating vortex of winds beneath a thunderstorm. Broadly, tornadoes in Florida occur within lines of thunderstorms ahead of an advancing cold front from the northwest, within single isolated thunderstorms, or within the rotating thunderstorms associated with a tropical cyclone (Hagemeyer 1997; Hagemeyer and Schmocker 1991; Gentry 1983). Since the atmosphere across Florida typically has enough water vapor to support thunderstorms due to its proximity to the Gulf of Mexico and the Atlantic Ocean, the essential ingredient for tornadoes are winds above the ground moving with increasing speeds and with veering directions (wind shear). The frequency of tornadoes in Florida rivals that of states better known for tornadoes including Kansas, Illinois, Iowa, and Oklahoma and the frequency is similar to other southern states including Mississippi, Alabama, and Louisiana (Table 1). The annual statewide tornado rate in Florida over the past 30 years is four reports per $10,000 \mathrm{~km}^{2}$, which is the same as in Kansas and which exceeds that in Oklahoma by $22 \%$.

Built structures in the path of a tornado are vulnerable to destruction from winds that can exceed $80 \mathrm{~m} \mathrm{~s}^{-1}$. Tornadoes are rated based on the severity of the worst structural damage found within the path. The rating is done with an ordered scale (EF-scale) from 0 to 5 (worst). The frequency of strong (EF2+) tornadoes in Florida is the lowest of the top ten tornado-prone states (Table 1). But strong tornadoes do occur in the state, including the April 1925 Miami Tornado which caused five deaths and produced damage totals that were estimated between $\$ 200$ and $\$ 300$ Thousand (1925 USD) (Gray 1925), which would be \$2.7-\$4.1 Million in 2014 dollars according to the U.S.

Bureau of Labor Statistics Consumer Price Index adjustment.

Knowing the range of possible future losses from tornadoes is important for insurance. There are two kinds of wind damage deductibles on an insurance policy in Florida: hurricane deductibles, 
which apply to damage solely from hurricanes, and windstorm or wind/hail deductibles, which apply to any kind of wind damage, including tornadoes. Structural property losses from past tornado events can be used to estimate the range of potential future losses but the variability is largely dependent on where the tornado occurs and how broad and intense the associated wind field. Changes to property value over time increase the difficulty in getting useful information about what could happen in the future.

The purpose of the study is to estimate tail statistics of potential total and residential property losses from tornadoes in Florida. Estimates are made by leveraging a new property value dataset from Florida's Department of Revenue and a simulation method afforded by spatial process modeling technology. The paper describes the data and methods and provides an estimate of annual expected and worse-case residential and non-residential exposures. In short, paths of tornadoes are placed on top of the property value cells to get an estimate of the structural property exposed to each tornado. The procedure answers the hypothetical question of what historical tornado, if it occurred in 2014, has the potential to cause the greatest amount of damage in terms of property loss because of where it occurred. Moreover, the sum of all per tornado exposures relative to 2014 divided by the number of years provides an estimate of the average annual exposure to the state. A statistical model for known losses from exposure together with a Monte Carlo procedure is used to get estimates of the probable maximum property loss.

\section{Data and methods}

\section{a. Florida property value data}

Tornadoes result in real estate financial losses. Risk assessment of property structural values is difficult due to the large number of individual properties and inconsistent tools for measure- 
ment. The dataset used in this study was developed to provide a consistent method for measuring property values across Florida. The source information is from the 2014 Florida Department of Revenue cadastral database. Property values are determined by each county's local property appraiser. Property values are aggregated to the U.S. National Grid 1-kilometer grid cells. Records include assessed property value, land value, and structural (material) value for all land use types and for residential parcels. The data is available through the Florida Resources and Environmental Analysis Center.

Interest centers on the residential and non-residential structural values in each grid cell, which are calculated by subtracting the land value from the assessed value then aggregating to the one$\mathrm{km}$ cell. At locations where the land value is unreasonable (e.g., it is zero or it is greater than the assessed value), the structural value is $90 \%$ of the assessed value. The total structural value is based on all land use categories and the residential structural value is based on the residential land use category only. The difference between the total and the residential value is the non-residential value.

\section{b. Tornado data}

The Storm Prediction Center's (SPC) database is the most readily available set of tornado records in the world. The database is compiled from the National Weather Service's (NWS) Storm Data, and includes all known tornadoes dating back to 1950. Tornado records contain information on initiation point (latitude and longitude), date, length and width of the damage path, and maximum damage rating on a scale from zero to five (Enhanced Fujita (EF) damage scale). They also contain an estimate of actual property loss in millions of dollars since 1996 and in whole dollar amounts since 2007. A zero value in the loss column does not necessarily mean no losses. 
Reports in the database are compiled by the NWS offices and reviewed by the National Centers

for Environmental Information (formerly known as the National Climate Data Center) Verbout et al. (2006). The database is available in a shapefile format with each tornado represented as a straight line track. The tornado track is the great circle line (no width) between the estimated start (initiation point) and end locations. Locations in the attribute table are recorded with two digit decimal precision prior to 2009 and four digit precision afterwards. Locations have greater precision later in the record when estimates are made with a Global Positioning System (GPS).

\section{c. Property Exposure and Losses}

For each tornado report in the database we estimate an approximate path by buffering the track using the width (Fig. 1). The average path widths given in the data set after 1995 are decreased by $25 \%$ to better match the average widths given in the database prior to that time (Grieser and Terenzi 2016). We then overlay the tornado path onto the cells containing the property values (see Fig. 2) to determine the per tornado exposure assuming the tornado occurs in 2014. We use the proportion of path area in each cell to apportion the structural property exposure for each tornado. The actual loss from a tornado should be less than the total property value in the path and will depend on many factors including the vulnerability of the structures to strong winds and the proportion of the path experiencing the strongest winds (Grieser and Terenzi 2016). These data are not available so we regress per tornado loss estimates available since 2007 (log scale) onto the logarithm of exposure controlling for year to determine the percentage change in losses for a percentage change in exposure. We use this average relationship to estimate losses from exposure.

To provide uncertainty bounds on the annual losses and to get an estimate of extreme losses we run a Monte Carlo simulation (Strader et al. 2014). The simulation randomly permutes locations, orientations, and path characteristics of the historical tornadoes to generate synthetic tornado 
paths. The simulation is done by year for 10,000 years where the number of tornadoes in a year is chosen from a Poisson distribution with a rate equal to the long-term annual rate of 49 per year. The synthetic paths are overlaid onto the exposure cells to determine exposure values, which are subsequently multiplied by the corresponding regression coefficients to obtain loss estimates. We use the proportion of path area in each cell rather than a simple intersection to apportion the structural property values.

\section{Results and Discussion}

There are 91,180 one-km cells with at least some structural property (Fig. 3). The statewide total structural value of all property is $\$ 942$ Billion and the total residential structural value is $\$ 619$ Billion. At the per cell level, the statewide average total value is $\$ 10$ Million with a median of $\$ 484,881$. The values are strongly right skewed (long right tail). The cell with the highest total structural value (\$8.8 B) includes Allen D. Nease Senior High School in Ponte Vedra, in St. John's County. The cell with the highest residential structural value $(\$ 411 \mathrm{M})$ includes the area around Lake Eola Park in downtown Orlando.

On average, residential property values exceed non-residential values (Fig. 4). The most common residential exposures at the cell level are between $\$ 100,000$ and $\$ 1,000,000$ while the most common non-residential exposures are between $\$ 50,000$ and $\$ 500,000$. The percentage of cells in the state with values exceeding $\$ 50 \mathrm{M}$ is $3.3 \%$ for residential values and $1.2 \%$ for non-residential values.

There are 3,233 tornado reports with genesis locations attributed to the state in the 66-year period 1950-2015 for an annual average of 49 reports per year. Sixty-one percent of the tornadoes are rated F/EF0 and $28 \%$ are rated F/EF1 (Table 2). There are only 37 F/EF3 and two F/EF4 reports 
since 1950. Frequency of tornadoes peaks in June with the June, July, and August being the three months most active for tornadoes in the state.

Slightly less than four percent of tornado paths have an area that exceeds one square $\mathrm{km}$. The total area of all paths with genesis in Florida is $713 \mathrm{~km}^{2}$, which is $.5 \%$ of the total area of the state. There is an upward trend in the annual total path area since 1988.

The total number of cells affected by tornadoes is 10,936 with 8,080 of the cells having been hit only once and 791 cells having been hit twice. The average number of tornadoes per cell with property is .12 with a minimum of zero $(82,020$ cells have never been hit) and a maximum of 20 (once every 3 or 4 years on average) in the Palmetto Park area of St. Petersburg likely due to the convergence of sea breezes from the Gulf of Mexico and Tampa Bay.

Averaging over all exposures we determine the annual property exposure is $\$ 156.6$ Million with \$94.4 Million of that as residential property. In contrast with tornado frequency, property exposure to tornadoes peaks in February with February, March, and April the three months with the highest average exposures. This is due to the fact that longer, and wider tornadoes tend to occur with springtime weather systems (Fuhrmann et al. 2014). While EF0 tornadoes account for 59\% of all Florida tornadoes they represent only $9 \%$ of the property exposure. In contrast, tornadoes rated EF2 or higher account for less than $12 \%$ of all tornadoes but $64 \%$ of residential and $69 \%$ of nonresidential property exposure. Twenty one percent of all residential and $17 \%$ of all non-residential property exposure is due to tornadoes associated with tropical cyclones.

Results from the regression of losses onto exposure reveal that a doubling of the residential exposure increases actual recorded losses by $26 \%$ since 2007 and a doubling of non-residential exposure increases losses by $20 \%$ controlling for changes over time (see Fricker et al. (2017); Ashley and Strader (2016)). The regression coefficients multiplied by the corresponding annual exposure rate indicates an annual expected loss of $\$ 48$ million. 
More relevant for insurance is the possibility of a big loss. We estimate the annual probable maximum loss (PML) as the value of the largest loss that could occur. Results from a Monte Carlo algorithm that randomly permutes the historical tornado paths indicate a $1 \%$ chance that the annual loss will exceed $\$ 430$ million and a .1\% chance that it will exceed $\$ 1$ billion (Fig. 5). For comparison, in 2016 there were 15 weather and climate disaster events with losses at or exceeding $\$ 1$ billion each across the United States (NCEI 2017) including the May 2nd and May 11th tornado outbreaks resulting in losses of $\$ 2.4 \mathrm{~B}$ and $\$ 1.7 \mathrm{~B}$, respectively.

\section{Conclusion}

Each year Florida sees property losses from tornadoes. The amount of loss varies widely depending on location, strength, and size of the tornado strike. This variability along with large changes in structural property values over time make it difficult to use historical losses to estimate future losses. In this study annual expected property losses from tornadoes in Florida are estimated by combining a one-km spatial grid of structural values from the Department of Revenue's 2014 cadastral database, a regression model for losses, and a geometric model for historical tornado events.

The annual statewide total and residential structural property exposure to tornadoes is estimated at $\$ 171$ million and \$103 million, respectively with the largest exposures occurring during the month of February. Using data since 2007 and controlling for changes over time, a doubling of the residential exposure was associated with a $26 \%$ increase in actual recorded losses and a doubling of non-residential exposure was associated with a $21 \%$ increase in actual losses. Results from a Monte Carlo algorithm that randomly permutes the historical tornado paths indicate a $1 \%$ chance that the annual loss will exceed $\$ 430$ million and a .1\% chance that it will exceed $\$ 1$ billion. 
These findings and the methodology to obtain them should be of wide interest to the property insurance and reinsurance industries, including the risk modeling companies, for helping them gauge the risk of losses and prioritize management actions. For instance, the probable worse case loss can help insurance underwriting decisions including the amount to cede to a re-insurer. The work can be expanded by examining exposures in other states and by considering the potential influence of climate factors (e.g., El Niño) on losses. It would also be of interest to consider how the changing characteristics of tornadoes (e.g., path length and clustering) influence the results in the future.

Acknowledgments. We thank Todd Moore from Towson University for his list of tornadoes from tropical cyclones. The data used in this study and all the code used in the analysis are available at http://rpubs.com/jelsner/FloridaPropertyLossesFromTornadoes. The authors received no specific funding for this work.

\section{References}

Ashley, W. S., and S. M. Strader, 2016: Recipe for disaster: How the dynamic ingredients of risk and exposure are changing the tornado disaster landscape. Bulletin of the American Meteorological Society, 97, 767-786.

Feuerstein, B., N. Dotzek, and J. Grieser, 2005: Assessing a tornado climatology from global tornado intensity distributions. J. Climate, 18, 585-596.

Fricker, T., J. B. Elsner, and T. H. Jagger, 2017: Population and energy elasticity of tornado casualties. Geophysical Research Letters, 44, 3941-3949, doi:10.1002/2017GL073093.

Fuhrmann, C. M., C. E. Konrad II, M. M. Kovach, J. T. McLeod, W. G. Schmitz, and P. G. Dixon, 2014: Ranking of tornado outbreaks across the United States and their climatological 
characteristics. Weather and Forecasting, 29, 684-701.

Gentry, R. C., 1983: Genesis of tornadoes associated with hurricanes. Monthly Weather Review, 111, 1793-1805.

Gray, R. W., 1925: The tornado of april 5, 1925, near miami, fla. Monthly Weather Review, 53 (4), 145-146, doi:10.1175/1520-0493(1925)53〈145:TTOANM $\rangle 2.0 . C O ; 2$.

Grieser, J., and F. Terenzi, 2016: Modeling financial losses resulting from tornadoes in European countries. Weather, Climate, and Society, 8, 313-326.

Hagemeyer, B. C., 1997: Peninsular Florida tornado outbreaks. Weather and Forecasting, 12, $398-426$.

Hagemeyer, B. C., and G. K. Schmocker, 1991: Characteristics of east central florida tornado environments. Weather and Forecasting, 6, 499-514.

NCEI, 2017: U.S. Billion-Dollar Weather and Climate Disasters. NOAA National Centers for Environmental Information (NCEI), Washington, DC, URL https://www.ncdc.noaa.gov/billions/.

Strader, S. M., W. S. Ashley, A. Irizarry, and S. Hall, 2014: A climatology of tornado intensity assessments. Meteorological Applications, 22, 1-10.

Verbout, S. M., H. E. Brooks, L. M. Leslie, and D. M. Schultz, 2006: Evolution of the U.S. tornado database: 1954-2003. Weather and Forecasting, 21, 86-93. 
Table 1. Tornado reports per 10,000 square $\mathrm{km}$ at the state level over the past 30 years

Table 2. Frequency and percentages of Florida tornado reports over the period 19502015. The US percentage is median percentage for all US tornadoes after 
TABLE 1. Tornado reports per 10,000 square $\mathrm{km}$ at the state level over the past 30 years (since introduction of Doppler radar). All tornadoes and EF2+ tornadoes.

\begin{tabular}{clcc}
\hline Rank & State & All Tornadoes & EF2+ Tornadoes \\
\hline 1 & Florida & 117 & 5 \\
2 & Kansas & 117 & 10 \\
3 & Mississippi & 106 & 18 \\
4 & Illinois & 100 & 13 \\
5 & Iowa & 99 & 12 \\
6 & Oklahoma & 96 & 13 \\
7 & Maryland & 94 & 6 \\
8 & Alabama & 92 & 16 \\
9 & Louisiana & 88 & 10 \\
10 & Nebraska & 79 & 8 \\
\hline
\end{tabular}


TABLE 2. Frequency and percentages of Florida tornado reports over the period 1950-2015. The US percentage is median percentage for all US tornadoes after Feurestein et al. (Feuerstein et al. 2005)

\begin{tabular}{cccc}
\hline EF Rating & FL Freq. & FL Perc. & US Perc. \\
\hline 0 & 1959 & 60.6 & 61.2 \\
1 & 917 & 28.4 & 27.4 \\
2 & 318 & 9.83 & 8.75 \\
3 & 37 & 1.14 & 2.06 \\
4 & 2 & 0.06 & 0.36 \\
5 & 0 & 0.00 & 0.05 \\
\hline
\end{tabular}


Fig. 1. Tornado paths. Paths of all known tornadoes affecting Florida over the period 1950-2015. . . 16

Fig. 2. Overlay tornado path on property value cells.

Fig. 3. Florida property values (2014). Values are aggregated to the U.S. National Grid at one-km resolution. Source: Florida Department of Revenue cadastral database. . . . . . . . 18

Fig. 4. Distribution of property values. Values are estimated in one-km cells and divided into residential and non-residential.

Fig. 5. Annual exceedance probabilities. Values are estimated using a Monte Carlo procedure that generates 10,000 years of synthetic tornado paths across Florida. 
FIG. 1. Tornado paths. Paths of all known tornadoes affecting Florida over the period 1950-2015.

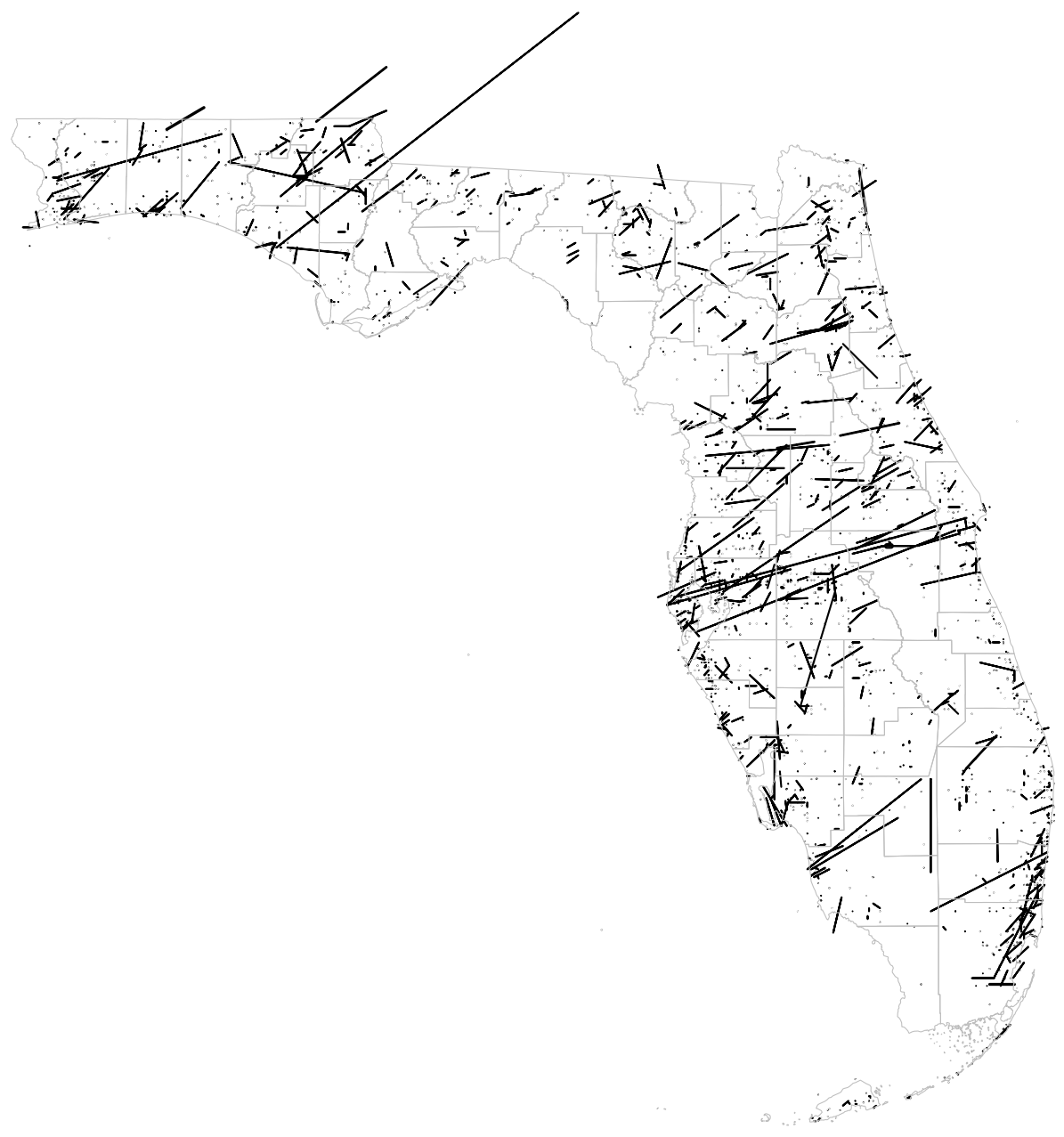


FIG. 2. Overlay tornado path on property value cells.

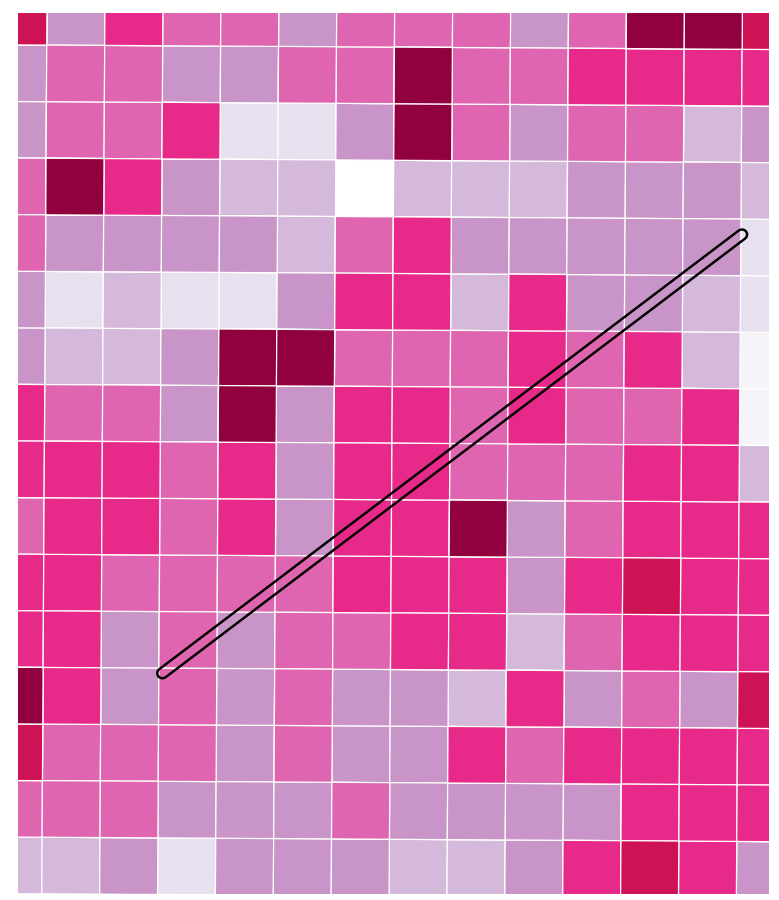


FIG. 3. Florida property values (2014). Values are aggregated to the U.S. National Grid at one-km resolution.

Source: Florida Department of Revenue cadastral database.

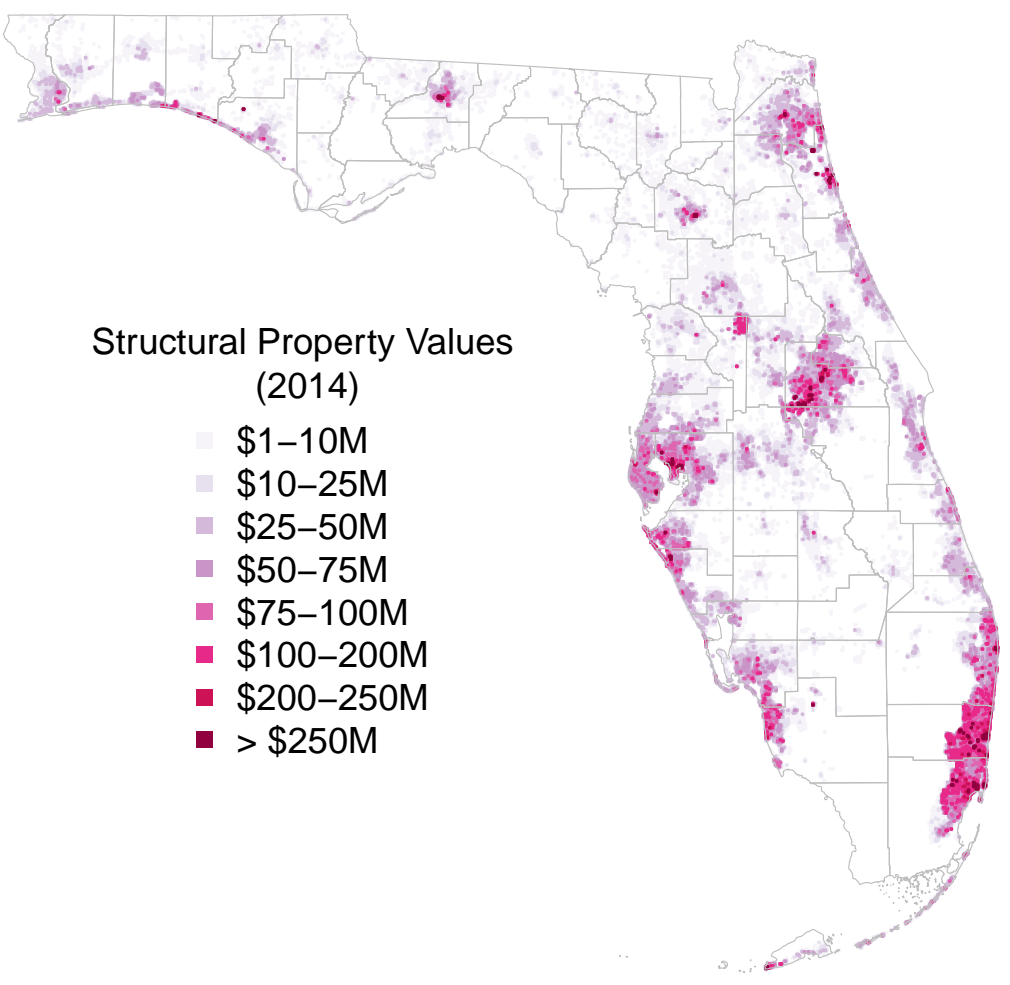


FIG. 4. Distribution of property values. Values are estimated in one-km cells and divided into residential and non-residential.

Florida Structural Values

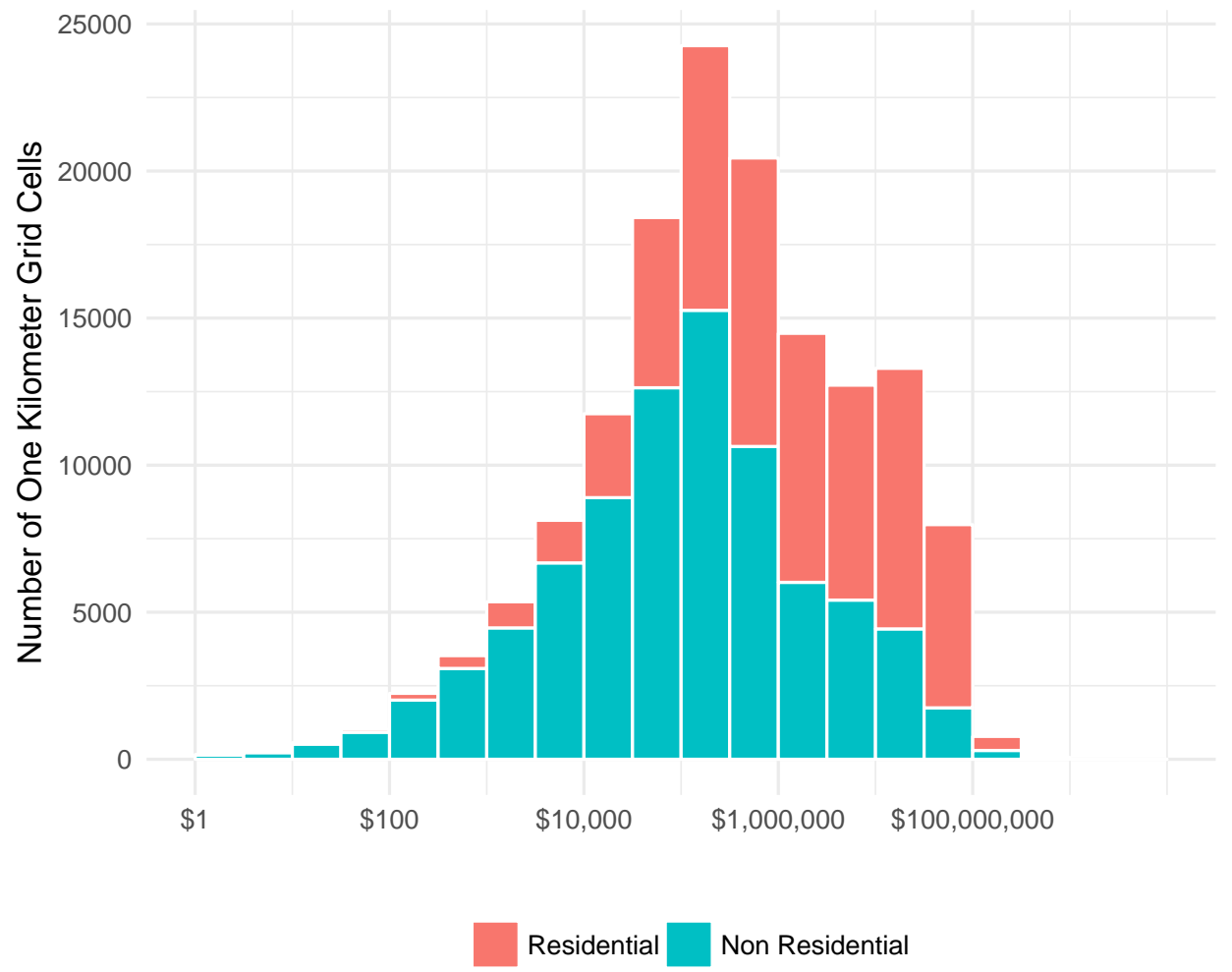


FIG. 5. Annual exceedance probabilities. Values are estimated using a Monte Carlo procedure that generates 10,000 years of synthetic tornado paths across Florida.

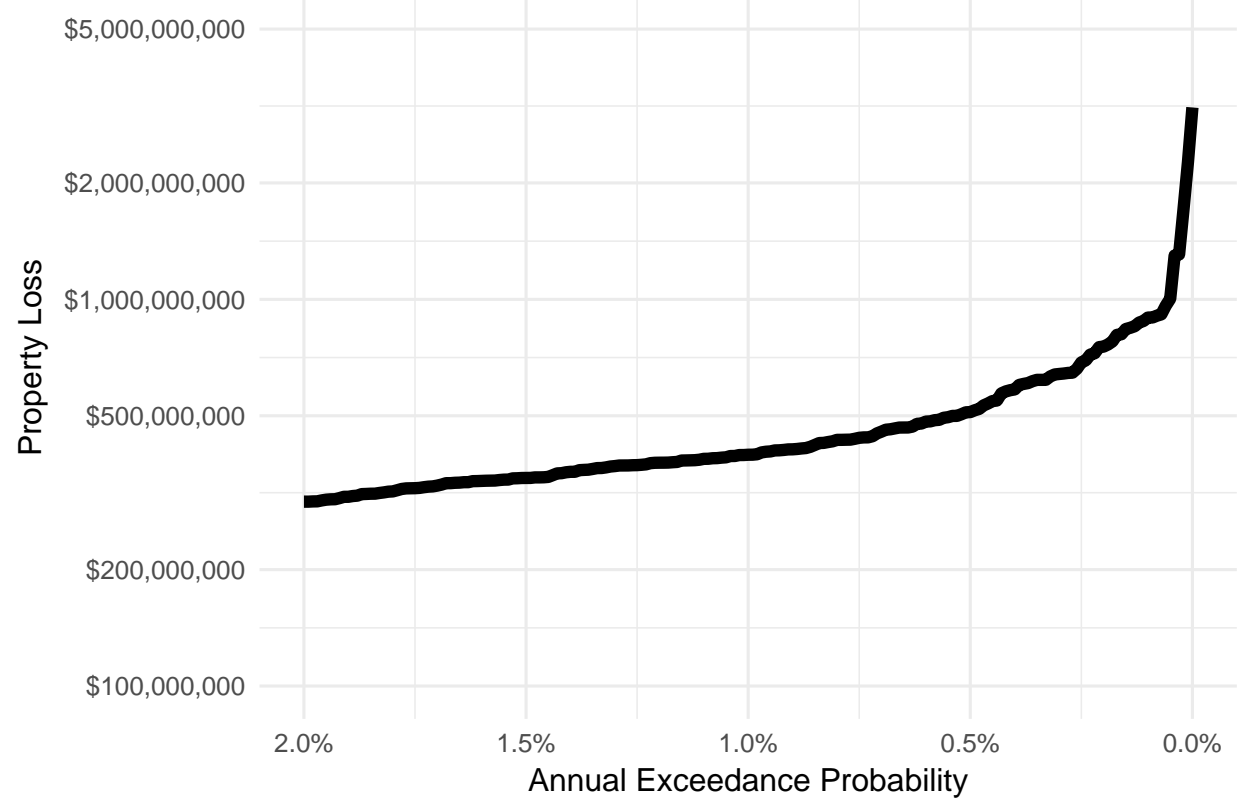

